\title{
ÜBER DEN SCHIFFBAU DER ALTEN ÄGYPTER
}

\author{
Peter P. Riesterer
}

Mit 1 Farbbild

Adolf Ervaxy erzählt in seinem Werk «̈̈gypten und ägyptisches Leben im Altertum»(Tübingen), daß auf dem Nil und seinen Kanälen auf Schiffen Lasten aller Art transportiert wurden, auf Schiffen alle Reisen zurückgelegt und selbst die Götterbilder bei Prozessionen auf Schiffen herumgefahren wurden - denn wie anders hätte ein Gott reisen können als zu Schiffe?

Aus den zahlreichen uns erhalten gebliebenen Abbildungen auf Denkmälern und in Grabkapellen, besonders aus dem Mittleren und Neuen Reich, kennen wir die Bauart der verschiedenen Nilschiffe, und auf der Darstellung einer Handelsexpedition der Königin Hatschepsut - vermutlich die älteste Expedition, die in der Geschichte Afrikas bezeugt ist - sie liegt beinahe 31⁄2 Jahrtausende zurück - sind die ägyptischen Schiffe zu sehen, die im Roten Meer in «hohe See» stachen.

Neben dem kleinen Nachen aus Papyrusstengeln, mit geringem Tiefgang und ohne Segel, hören wir schon im Alten Reich von Breitschiffen aus Akazienholz von 60 Ellen Länge und 30 Ellen Breite. Mit ihnen wurden die für den Pyramidenbau notwendigen Steinblöcke über den Fluß getragen. Das öfter wechselnde Fahrwasser des Nils ließ den Bau von Schiffen mit nur geringem Tiefgang zu. Ihr Hinterteil ragte steil aus dem Wasser auf, was Ermann wie folgt begründet: «Einerseits gewährt ein solches Hinterteil bei den kleinen Booten, die nicht gerudert, sondern «gestakt» werden, dem Stoßenden einen guten Halt; anderseits aber - und das ist wohl die Hauptsache - macht es diese Bauart möglich, leicht von den Sandbänken abzukommen, denen ja keiner ganz entgeht, der einen Tag auf dem Nil fährt.»

Schon im Altertum hatten alle größeren Schiffe außer dem Ruder auch ein Segel von rechteckiger Gestalt, anfänglich vermutlich aus Papyrusmatten, später durch Leinen ersetzt. Der Mast bestand anfänglich aus zwei Stangen, deren Spitzen oben zusammengebunden wurden. Noch im Alten Reich ersetzte sie ein starker Balken, den die Ägypter bei anderen seefahrenden Völkern kennengelernt haben dürften.

Schon im Alten Reich sprach man von Breitschiffen, Achtschiffen und Schleppschiffen. Sie wurden aus hellgelbem, vermutlich ausländischem Nadelholz gebaut. Hinter dem Mastbaum befand sich die Kajüte, deren Bedachung und Wände aus geflochtenen Matten oder aus weißer Leinwand gebildet wurden. Die Steuerung erfolgte mittels langer Lenkruder, später wurde dieses durch ein großes Steuer ersetzt; die Ruder sitzen nun auf Böcken, und die Kajüte dient zugleich als Aufenthalts- und Wohnraum.

Hatten im Alten Reich größere Schiffe von etwa 16 Meter Länge einen Mast von 10 Meter und eine Raa von 6 Meter, so wurde im Mittleren Reich, aus welchem unsere Abbildung stammt, bei einzelnen Schiffen der Mast auf etwa 5 Meter gekürzt, während die Raa ihre Länge beibehielt. Im Neuen Reich verlängerte man die Raa auf die doppelte Höhe des Mastes.

Aus dem Mittleren Reich (um 20+0-1710 v. Chr.) wurden uns zahlreiche Grabbeigaben überliefert: Spinner und Weber bei der Arbeit, Soldaten mit Schildern und Lanzen, Modellbauten von Häusern und Fischerbooten mit Nilfischen im Netz, sowie ein Modellboot mit Leinensegel aus dem Grabe des Meketre (11. Dynastie, Dêr ElBahri) in Oberägypten: Ein verhältnismäßig kleines Schiff, an welchem Ruder, Kajüte, Steuer, Segel und Schnurwerk gut erkennbar sind. Das Segel entspricht in seiner Breite der Hälfte des Mastes. Die Beigabe von Modellen und Uscheptis, kleinen Figürchen, die im Jenseits für den Toten die Arbeit verrichten sollten, gehören zur damaligen Vorstellung vom Weiterleben nach dem Tode. Wir verdanken also der Jenseitsvorstellung der Alten Ägypter teilweise weitgehende Kenntnisse vom Leben in Ägypten in jener Zeit. 
Modellboot mit Leinensegel; aus dem Grab des Meketre, 11. Dynastie. Aus der Nekropole von Dêr El-Bahri (Oberägypten), dem Buche «Das Ägyptische Museum Kairo», mit einer textlichen Einführung und Bilderklärungen von Peter P. Riesterer (Verlag Kümmerly \& Frey, 1963) entnommen. 


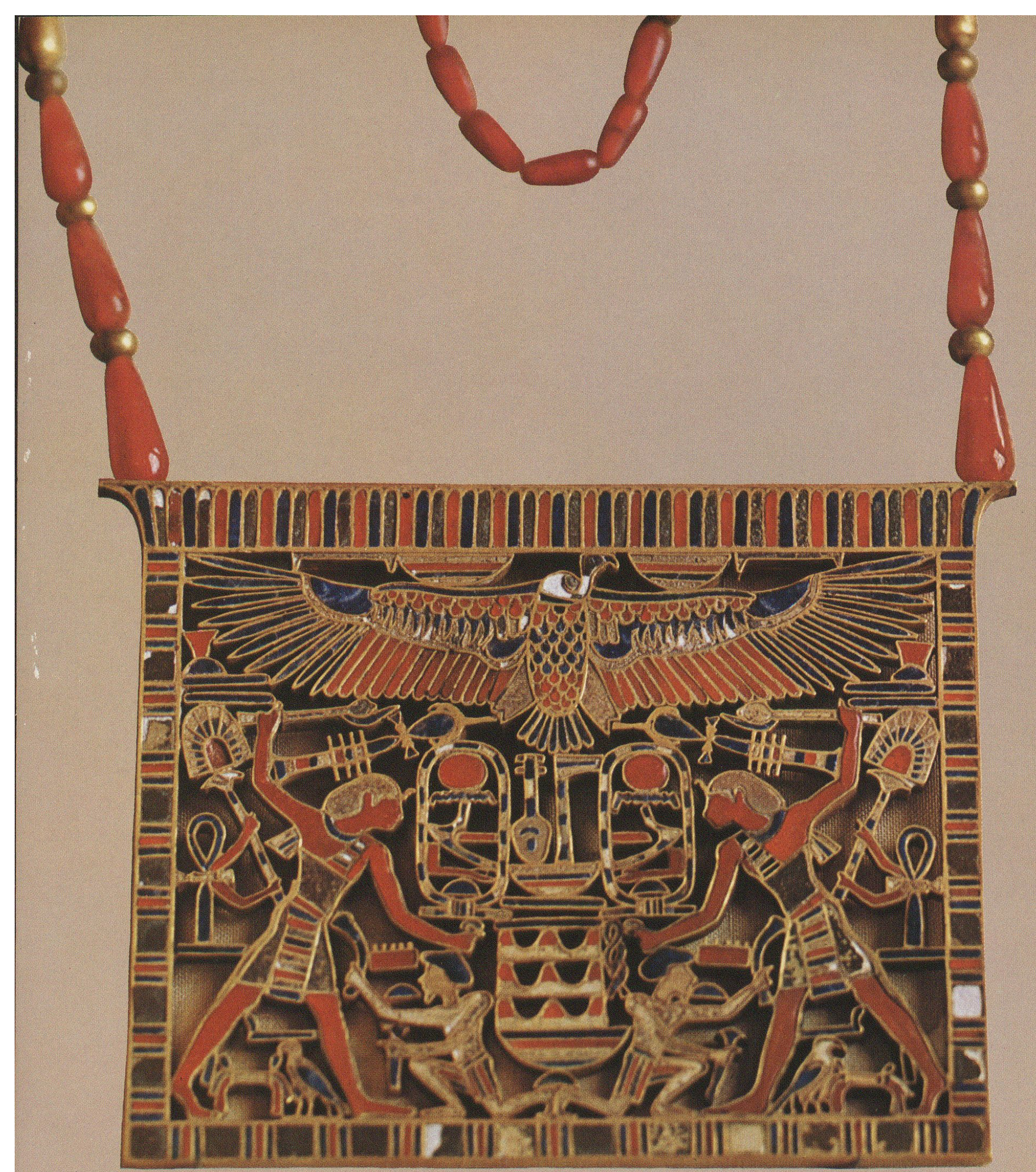

